Relations industrielles

Industrial Relations

\title{
Un directeur du personnel S.V.P.
}

\section{Gérard Tremblay}

Volume 4, numéro 2, octobre 1948

URI : https://id.erudit.org/iderudit/1023433ar

DOI : https://doi.org/10.7202/1023433ar

Aller au sommaire du numéro

Éditeur(s)

Département des relations industrielles de l'Université Laval

ISSN

0034-379X (imprimé)

1703-8138 (numérique)

Découvrir la revue

Citer cet article

Tremblay, G. (1948). Un directeur du personnel S.V.P. Relations industrielles / Industrial Relations, 4(2), 15-16. https://doi.org/10.7202/1023433ar

Tous droits réservés @ Département des relations industrielles de l’Université Laval, 1948
Ce document est protégé par la loi sur le droit d'auteur. L’utilisation des services d'Érudit (y compris la reproduction) est assujettie à sa politique d'utilisation que vous pouvez consulter en ligne.

https://apropos.erudit.org/fr/usagers/politique-dutilisation/ 


\title{
UN DIRECTEUR DU PERSONNEL S. V. P.
}

\author{
GÉrard Tremblay
}

Le développement de l'industrie et du commerce a sorti l'entreprise du cadre artisanal et l'a transformée en société anonyme. Forcément les relations personnelles entre employeurs et salariés ont cessé d'exister ou presque. Une hiérarchie rigide s'est développée de l'ouvrier au contremâ̂tre, du contremaître au chef de département, de celui-ci au gérant et de ce dernier au chef de l'entreprise et nous en passons . . . La décentralisation des responsabilités, l'ordonnance de la production, l'importance des effectifs ouvriers ont rendu inévitable cette brisure dans les relations personnelles entre la direction et les travailleurs.

Il est possible de combler cette brisure par l'organisation d'un service du personmel et de plus en plus rares, aujourd'hui, sont les établissements industriels et commerciaux d'importance qui en sont dépourvus. Si l'employeur averti n'hésite pas à établir un service spécialisé pour l'achat et l'entretien de ses machines, pourquoi hésiterait-il à aménager scientifiquement ses relations avec l'élément le plus important de la production: le travail ?

Quelles sont en bref les fonctions d'un bureau du personnel? Elles doivent être conditionnées par les exigences humaines et techniques de l'entreprise.

Au départ et dans le cours de son développement, une entreprise a besoin de travailleurs. Se pose donc le problème de leur recrutement. On ne recrute pas son personnel à l'aveuglette pas plus qu'on n'achète de machines à l'oeil. Le recrutement doit être suivi de la sélection. Celleci ne peut se faire qu'après une entrevue sérieuse des recrues ou des candidats. Conversations, étude des antécédents, examen des goûts et des dispositions, tests physiologiques et psychiques, références et diplômes, on devra recourir à tous les procédés qui permettent une appréciation des qualités du candidat. Intervient alors le placement du nouvel embauché dans une section de l'entreprise. Ce nouvel employé a besoin d'être initié ou pour le moins adapté à son travail. Il appartient à la direction du personnel de voir, en collaboration avec les contremaîtres ou les moniteurs, à faciliter l'entraînement ou l'adaptation de la nouvelle recrue.
Un candidat sélectionné avec soin fera bien son travail et s'y plaira. Conséquence, il n'aura pas l'idée de quitter son emploi après quelques semaines de mauvais service. Sait-on qu'il en coûte de $\$ 300$. à $\$ 1,000$. pour initier quelqu'un à un travail semi-qualifié? Jusqu'à $\$ 2,000$., s'il s'agit de travail qualifié ? Qui paie la note en cas de mauvaise orientation? L'employeur certes, dans une large mesure, car son investissement est perdu. L'on sait par ailleurs qu'un mouvement de personnel trop considérable amène la déchéance d'une entreprise. Le travailleur lui-mème y perd temps, argent et courage.

Le directeur du personnel diligent verra $\dot{a}$ réduire l'absentéisme à des minima incompressibles. Surveillance, sanctions, primes, éducation, service social, tout sera utilisé pour réduire ce fléau de l'industrie moderne qui s'affirme surtout et pour cause, en période de prospérité.

L'industrie expose les ouvriers aux accidents. Dans le Québec seulement, nous avons atteint le pallier de 100,000 accidents par années. Le chiffre peut en être réduit. Le bon directeur de personnel verra à mettre sur pied un comité de sécurité dans tous les départements, à relever les causes des accidents et à les prévenir. Là encore, économie d'argent pour l'employeur et l'ouvrier sans oublier la prévention des douleurs physiques, des mutilations et des angoisses.

Par association d'idées, nous sommes amenés à parler de l'organisation du service médical qui doit collaborer avec la direction du personnel.

L'examen médical d'aptitude à l'emploi complète la fiche personnelle et permet une sélection mieux appropriée du personnel. C'est rendre service à un candidat à une situation dans l'industrie que de lui révéler son état de santé déficient. Il pourra se diriger vers d'autres activités mieux appropriées à son état. L'employeur tarit ainsi à sa source des causes d'absentéisme et d'accidents toujours possibles. Bien plus, l'examen médical périodique devrait être de rigueur dans certaines entreprises. Prévention ne vaut-elle pas mieux que cure?

L'ouvrier est un être humain. Il aura parfois des griefs. Le contremaître en sera peut-être la 
cause. Comment pourra-t-il y apporter règlement juste et prompt s'il est lui-même partie au litige? Le directeur du personnel fera une enquête objective et indiquera la solution équitable. De même, s'il s'agit de promotions ou de mutations. L'entreprise, même si une convention collective régit les rapports entre la direction et le syndicat, aura besoin du concours de son directeur du personnel pour lui donner toutes informations utiles sur les candidats à des promotions ou mutations. Le fichier constitue, en l'occurrence, une source d'informations précieuses pour aider la direction à prendre une sage décision pour ellemême comme du reste pour l'employé concerné.

Le directeur du personel doit-il participer à la négociation de la convention collective? Jamais directement. Il doit être en mesure de fournir aux deux parties les renseignements sur la législation ouvrière ou d'ordre statistique dont elles peuvent avoir besoin. Il limitera son rôle à cette collaburation. Le directeur du personnel est essentiellement le conseiller du personnel et de l'entreprise. A ce titre, il doit maintenir une certaine indépendance à l'égard des parties; toutes deux doivent réaliser qu'il est leur conseiller désintéressé. Le vrai directeur du personnel s'efforce d'établir une communauté de travail entre employeurs et salariés. Il est essentiel qu'il garde la confiance des deux groupes. Notre expérience nous révèle qu'une industrie qui met en première ligne son directeur du personnel dans la négociation d'une convention collective et dans tout débat important sur sa mise en application, le prostitue et le tue. Le directeur du personnel n'est pas un garde-chiourme mais avant tout l'ambassadeur de l'entreprise auprès des salariés et vice versa.

Tout ce qui est humain et social ne doit pas rester étranger au directeur du personnel. S'agit-il de lancer une campagne d'éducation auprès des travailleurs en vue d'augmenter leur compétence! S'agit-il de l'organisation de cours du soir, de cours de sécurité, de premiers soins aux blessés! S'agit-il de l'éducation psychologique des contremaîtres! S'agit-il de fonder une bibliothèque technique, une revue! S'agit-il enfin d'organisation sportive, de fêtes sociales, le directeur du personnel doit être l'initiateur et le collaborateur discret. Rien de ce qui est humain et social ne doit lui rester étranger.

Beaucoup d'employeurs et de plus en plus d'organisations syndicales se préoccupent aujourd'hui de sécurité sociale au sein de l'entreprise : organisation d'assurance-maladie y compris la couverture des frais d'hospitalisation; primes à l'occasion du mariage, de la naissance d'un enfant, etc. Voilà encore un champ d'activités tout réservé au bureau du personnel.

On imagine facilement la masse de documentation précieuse que peut accumuler un directeur du personnel averti, actif et à qui on laisse les coudées franches, s'il n'en abuse pas. On imagine surtout les merveilleuses réalisations qu'il peut avoir à son crédit et reporter sur le bon nom de l'entreprise et des travailleurs qu'il sert.

Notre Département des relations industrielles se préoccupe de former des directeurs de person. nel compétents. Déjà, il se réjouit, malgré son jeune âge, d'avoir fourni d'excellents résultats à d'importantes entreprises qui se félicitent d'avoir sollicité sa collaboration. Ces entreprises y ont trouvé non seulement un profit matériel mais le sentiment qu'elles ont établi avec leur personnel des relations vraiment humaines qui se traduisent par le bonheur de leurs employés, un bel esprit de famille et le triomphe d'une charité sociale bien comprise.

On ne s'improvise pas directeur du personnel. Et c'est précisément ce qui a un peu gâté le bon renom des directeurs du personnel d'avoir forcément recueilli au sein de la profession des personnes bien intentionnées mais mal préparées au point de vue technique et psychologique à leurs lourdes responsabilités.

\section{Farmes de callabaration patronale-anurière}

Le Rapport du troisième Congrès des relations industrielles de Laval (1948) contenant le texte des conférences et des délibérations est maintenant en vente au prix de $\$ 1.50$ (franco). Sujets traités: La convention collective (Me Paul Lebel); La formation professionnelle (Gabriel Rousseau); Les comités d'entreprises (Raymond Gérin); La sécurité du travail, la médecine et lhygiène industrielles (Dr Wilfrid Leblond); Théologie du travail (T.R.P. Georges-Henri Lévesque o.p.) 